\title{
GRUPO FOCAL COMO FORMAÇÃO CONTINUADA DE PROFESSORES
}

\author{
Vivian Miné Geraldo Garcia ${ }^{1}$ \\ Luciana de Oliveira Rocha Magalhães ${ }^{2}$ \\ Suelene Regina Donola Mendonça ${ }^{3}$
}

Resumo: O presente artigo faz parte da dissertação em andamento "ATUAÇÃO EM SALA DE RECURSOS MULTIFUNCIONAIS: ações desenvolvidas no contexto escolar". Tal pesquisa, de cunho qualitativo e exploratório, tem como finalidade delinear as principais ações desenvolvidas pelos docentes do Atendimento Educacional Especializado (AEE) em Sala de Recursos Multifuncionais (SRM) de um município paulista do Vale do Paraíba. Para a coleta de dados teve como técnica o Grupo Focal, que oportunizou a esses docentes a reflexão sobre a própria atuação, num processo de formação continuada. O resultado apresenta uma exposição e análise sobre a atuação docente e os saberes essenciais que regem suas ações profissionais. Durante as discussões no grupo focal, demos voz ao professor, oportunizando a construção de conhecimento dialético e conjunto. Pretende-se demonstrar a importância da utilização de grupos focais em pesquisas qualitativas, agregando formação e autoconhecimento.

Palavras-chave: Grupo focal; Formação continuada; Atendimento educacional especializado; Sala de recursos multifuncionais.

\footnotetext{
${ }^{1}$ Programa de Pós Graduação e Mestrado da Universidade de Taubaté/Universidade de Taubaté, Programa de Pós Graduação e Mestrado da Universidade de Taubaté, Brasil. E-mail: vivianmine@hotmail.com.

2 Programa de Pós Graduação e Mestrado da Universidade de Taubaté/Universidade de Taubaté, Programa de Pós Graduação e Mestrado da Universidade de Taubaté, Brasil. E-mail: lucianam11@hotmail.com.

3 Programa de Pós Graduação e Mestrado da Universidade de Taubaté/Universidade de Taubaté, Programa de Pós Graduação e Mestrado da Universidade de Taubaté, Brasil. E-mail: profa.suelene@gmail.com.
} 